\title{
Nadir Bir Olgu: Persistant Metopik Sütür
}

\author{
A Rare Case: Persistant Metopic Suture
}

Yalçın AKBULUT, Muhammed Bora UZUNER, Erengül BODUÇ, Aslı Beril KARAKAŞ

Kafkas Üniversitesi Tip Fakültesi, Anatomi ABD, Kars

Geliş tarihi: 14.12.2019 Kabul tarihi: 29.01.2020 DOI: 10.17517/ksutfd.659477

Özet

Sutura metopica, bregma’dan nasion'a kadar uzanan ve normalde 8 yaşına kadar kapanması gereken bir sütürdür. Bu iki antropolojik nokta arasında kesintisiz devam eden sütürlere ise sutura frontalis persistens adı verilir. Kafkas Üniversitesi Tıp Fakültesi Anatomi Ana Bilim Dalı’na ait 20-30 yaşlarında ve erkek 12 adet kafatasının birinde sutura frontalis persistens tespit edildi. $12.35 \mathrm{~cm}$ uzunluğundaki sütürün ilk $7.62 \mathrm{~cm}$ 'lik kısmının testere ucu şeklinde, son $4.73 \mathrm{~cm}$ 'lik bölümünün ise düzensiz bir çizgi şeklinde olduğu saptandı. Sutura metopica’nın sutura sagittalis'in sonu ile birleştiği fakat sutura internasalis ile kesişmediği tespit edildi. Kafatasında sağ ve sol frontal sinüslerin mevcut olduğu belirlendi. Bu olgu sunumunun amacı, frontal bölge ile ilgili yapılacak anatomik, arkeolojik ve cerrahi uygulamalarda nadir görülen sutura metopica’nın varlığını ve varyasyonlarının önemini bir kez daha hatırlatmaktır.

Anahtar Kelimeler: Sutura metopica, metopizm, frontal kemik

\begin{abstract}
Metopic suture is a suture extending from bregma to nasion and should normally be closed by the age of 8 years. Continuous sutures between these two anthropological points are called persistant metopic sutures. A persistent metopic suture was detected in one of 12 male skulls, 20-30 years old, belonging to the Department of Anatomy, Faculty of Medicine, Kafkas University. It was found that $7.62 \mathrm{~cm}$ of the $12.35 \mathrm{~cm}$ long suture was saw-shaped and $4.73 \mathrm{~cm}$ was an irregular line. The metopic suture was found to merge with the end of the sagittal suture but did not intersect with the internal suture. There were right and left frontal sinuses in the skull. The aim of this case report is to remind once again the existence of rare metopic sutures and the importance of variations in anatomical, archaeological and surgical applications of the frontal region.
\end{abstract}

Key words: Metopic suture, metopism, frontal bone

Yazışma Adresi: Yalçın AKBULUT Kafkas Üniversitesi Tıp Fakültesi, Anatomi ABD, Kars Mail: yalcinakbulut@kafkas.edu.tr

ORCID No (Sirasıyla): 0000-0003-4661-2224, 0000-0001-6557-3086, 0000-0001-8872-1993, 0000-0001-6504-6489 


\section{GİRiş}

Calvarium, frontal, occipital, parietal, ve temporal kemiğin pars squamasa'sının koronal, lambdoid, skuamal, sagital ve metopik sütürler vasıtasıyla birleşmesiyle oluşur. Ayrıca oksipital kemikte inkompletmendozal sütürler bulunmaktadır. Metopik ve sagital sütürler tek, koronal, lambdoid ve skuamal sütürler ise çifttir. Sütürlerin ve fontanellerin esnekliği, doğum esnasında, kafa kemiklerin üst üste binmesini ve bebeğin başının doğum kanalı içinden daha rahat bir şekilde geçebilmesini sağlar (1-5).

Sutura metopica, frontal kemiğin iki yarısında kemikleşmenin başarısızlığıyla oluşan vertikal bir sütür olup, frontal tuber düzeyinde kaybolmaya başlamaktadır. Sutura metopica, 3-9 ay arasında önden arkaya, glabella noktasindan fonticulus anterior’a doğru kapanırken, diğer sütürler arkadan öne ve dış kesimlerden içe ve ortaya doğru kapanır. Sutura metopica’nın kapanması genelde doğumdan sonraki bir buçuk ile sekiz yaşları arasındadır. (6-8). Sutura metopica, eğer bregmadan nasion'a kadar kesintisiz bir şekilde devam ediyorsa persistant metopik sütür ismini alır ve bu durum metopizm olarak adlandırılır. Kraniyal kemiklerin anormal gelişimi, genetik nedenler, kalıtımsal olarak büyümenin durması, seksüel ve hormonal etkiler, atavizm, kraniyal malformasyon ve hidrosefali gibi bazı durumlarda sutura metopica tamamen kapanmaz. Ayrıca sutura metopica'nın erken dönemde kaynaşması ile metopik sinostoz şekillenir ve bu durum trigonosefali ile sonuçlanabilir (8-9).

Literatürde Avrupa, Afrika, Asya ve Avusturalya'da, farklı etnik kökenler üzerinde yürütülen çalışmalarda persistant metopik sütür görülme olasılığının \%1-10 arasında olduğu belirtilmiştir. (10-13). Bu çalışma, persistant metopik sütür'ün kısmen de olsa morfolojik özelliklerini ortaya çıkararak ileride yapılacak anatomik ve arkeolojik araştırmalara katkı sağlamak ve frontal kraniotomi gibi klinikte kafa travmalarına yaklaşımlarda nadir rastlanılan bu sütürün varlığ1nı bir kez daha hatırlatmak amacı ile yapılmıştır.

\section{OLGU SUNUMU}

Kars Müzesi'nden 05.06.2018 tarihli ve E.487086 sayılı izinle Kafkas Üniversitesi Tıp Fakültesi Anatomi Ana Bilim Dalı'na eğitim amacıyla verilen 20-30 yaşlarında ve erkek 12 adet kafatasının birinde persistant metopik sütür tespit edildi. Bu kafatasında herhangi bir Wormian kemiğe (ossa suturalia) ve kraniosinostoz’a rastlanılmadı. Persistant metopik sütür'ün, bregma'dan nasion'a kadar olan uzunluğu $12.35 \mathrm{~cm}$ olarak ölçüldü. Uzunluğunun ilk $7.62 \mathrm{~cm}$ 'inde testere ucu şekilde bir görünümde olduğu, son $4.73 \mathrm{~cm}$ 'sinin ise düzensiz bir çizgi şeklinde devam ederek sonlandığı saptandı. Sutura metopica’nın sutura sagittalis'in sonu ile birleștiği fakat sutura internasalis ile kesişmediği tespit edildi (Resim 1) . Kafatasında sağ ve sol frontal sinüslerin mevcut olduğu belirlendi. Ölçümlerde (0.01,BTS. Eng) dijital kumpas kullanıldı.

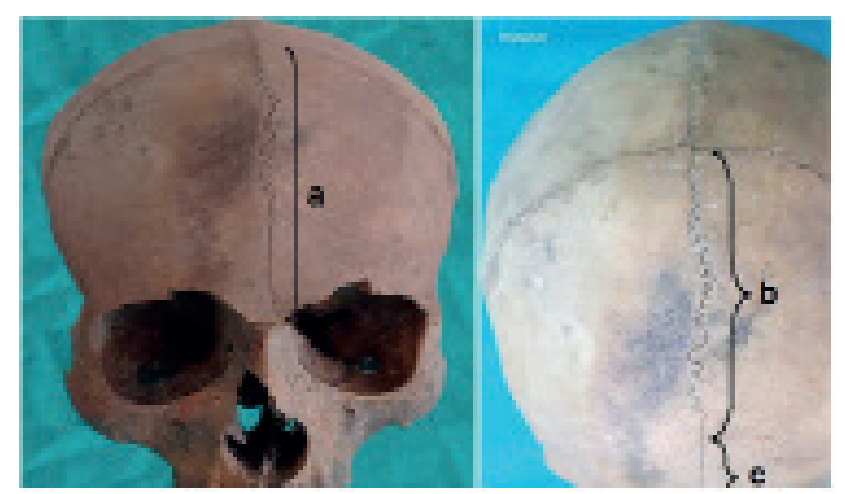

Resim 1. Sutura metopica'nın farklı açılardan görünümü a)Sutura metopica, b) Testere ağzı görünümü, c) Düzensiz bir çizgi görünümü

\section{TARTIŞMA}

Literatürde, sutura metopica’nın sınıflandırılması, görülme sıklığ 1 , bazı morfolojik ve morfometrik özellikleri ve frontal sinüs ile ilişkisi üzerine farklı çalışmalar yer almaktadır (1416).

Çalışmamızda 12 kafatasının birinde sutura metopica'ya rastlanılır iken, Türkiye'nin farklı bölgelerinde yapılan çalışmalar da ise Aksu ve ark. (15) Batı Anadolu'da 160 adet kuru kafatasının 12'sinde (\% 7.5) ve Bilgin ve ark. (16) ise Doğu Anadolu'da BT ve MR kullanarak yaptıkları çalışmada 631 insanın 61'inde (\% 9.7) sutura metopica tespit etmişlerdir.

Sutura metopica'nın ortalama uzunluğunu, Skrzat ve ark. (17) $12.31 \mathrm{~cm}$, Yadav ve ark. (18) $12.80 \mathrm{~cm}$, Das ve ark. (19) $12.10 \mathrm{~cm}$ ve Bilodi ve ark. (20) $11.50 \mathrm{~cm}$ olduğunu belirtmişlerdir. Olgumuzda ise sütürün uzunluğu diğer çalışmalara benzer şekilde $12.35 \mathrm{~cm}$ olarak belirlendi.

Arıncı ve Elhan (1), sutura metopica'yı düzenli bir testere ağzına benzetir iken, Nikolava ve ark. (21) tarak şekline benzetmişlerdir. Olgumuzdaki sutura metopica’nın ilk 7.62 cm'inde bu benzetmelere uygun bir şekilde devam ettiği fakat son $4.73 \mathrm{~cm}$ 'de ise hattı düzgün olmayan bir çizgi halinde sonlandığı belirlenmiştir.

Halagatti ve ark. (14) 282 kafatasının 17'sinde (\% 6.02) Aksu ve ark. (15) ise 160 kafatasının 12'sinde (\%7.5) sutura metopica’nın bregma’dan nasion'a kadar tam bir seyir izlediğini belirtmişlerdir. Ayrıca Aksu ve ark. (15) 12 kafatasından 3'ünün internasal sütür ile 2'sinin ise sagital sütür ile birleştiğini belirtmişlerdir. Olgumuzdaki sutura metopica’nın bu siniflandirmaya göre bregma'dan nasion'a kadar kesintisiz olarak devam ettiği ve sagital sütür ile birleștiği fakat internasal sütürle birleşmediği belirlendi.

Bilgin ve ark. (16) 631 kafatasının 61'inde (\% 9.7) sutura metopica saptanmış olup, 61 kafatasının 29'unda sağ, 8'inde sol ve 24 'ünde ise iki taraflı frontal sinüs atrofisine rastlanılmıştır. Olgumuzda ise her iki frontal sinüsün de mevcut olduğu belirlendi.

Göksal (22), 20-30 yaşında yetişkin bir kadın kafatasında sutura metopica'nın morfolojik incelemesinde frontal kemi- 
ğin dış ve iç yüzündeki sütür uzunluklarını sırasıyla 5.42 ve $4.49 \mathrm{~cm}$ olarak belirlemiștir. Olgumuzda ise sütürün frontal kemiğin her iki yüzünde aynı seyir izlediği ve uzunluklarının da aynı olduğu görülmüştür.

Sonuç olarak bu tür nadir varyasyonların varlığının bilinmesinin adli tıpta, arkeolojik kazılarda, radyolojik görüntülemede ve klinikte kafa travmaları ile ilgili yapılacak olan teşhis ve tedavide hataya düşülme ihtimalini önleyeceğini düşünüyoruz.

\section{KAYNAKLAR}

1. Arıncı K, Elhan A. Anatomi, 1. Cilt, Güneş Kitabevi, Ankara, 2014;30-42.

2. Gallagher ER, Evans KN, Hing AV, Cunningham ML. Bathrocephaly A head shape associated with a persistent mendosal suture. Cleft Palate Craniofac J. 2013;50:104-108.

3. Jin SW, Sim KB, Kim SD. Development and growth of the normal cranial vault: An embryologic review. J Korean Neurosurg Soc. 2016;59:92-96.

4. Opperman LA. Cranial sutures as intramembranous bone growth sites. Dev Dyn. 2000; 219: 472-475.

5. Badve CA, K MM, Iyer RS, Ishak GE, Khanna PC. Craniosynostosis: Imaging review and primer on computed tomography. Pediatr Radiol. 2013;43:728-742.

6. Nayakanati ARJ, Bamur BM, Rao MVR. A Study of incidence of metopic suture in adult human dry skulls. Int J Anat and Res 2016;4:2235-2237.

7. Saheb HS, MavishetterGF, Thomas ST, Prasanna LC. Incidence of metopic suture in adult South Indian. J Biomed Sci Res. 2010;2:223-236.

8. WadekarPR, PundgeSJ, FulpatilMP, PanditSV. Study of incidence of metopic suture in adult skulls. Indian J Basic Appl Med Res. 2014;4:277-280.

9. Jaskolka, MS. Current controversies in metopic suture craniosynostosis. Oral Maxillofacial Surg N Am. 2017;29: 449.

10. Berry AC. Factors affecting the incidence of non-metrical skeletal variants. J Anat. 1975;120:519-535.

11. Agarwal SK, Malhotra VK, Tewari SP. Incidence of the metopic suture in adult Indian crania. Acta Anat (Basel). 1979;105:469474.

12. Ajmani ML, Mittal RK, Jain SP. Incidence of the metopic suture in adult Nigerian skulls. J Anat. 1983;137:177-183.

13. Breathnach A. S. Frazer's Anatomy of the Human Skeleton, Churchill, London: 5th edition, 1958.

14. Halagatti M, Sagar S, Gouda C: Incidence of metopic suture in dry adult cadaveric skulls its morphology and importance. Indian J Clin Anat Physiol. 2017;4:532-537.

15. Aksu F, Çırban S, Göçmen Mas N, Karabekir S, Mağden A. O: Anatomic features of metopic suture in adult dry skulls. J Craniofacial Surg. 2014;25:1044-1045.

16. Bilgin S, Kantarcı UH, Duymus M, Yildirim CH, Ercakmak B, Orman $\mathrm{G}$ et al. Association between frontal sinus development and persistent metopic suture. Folia Morphol. 2013;72:306-310.

17. Skrzat J, Walocha J, Zawilinski J. A note on the morphology of the metopic suture in the human skull. Folia Morphol (Warsz). 2004;63:481-484.

18. Yadav A, Kumar V, Srivastava RK. Study of Metopic suture in the adult human skulls of North India. J Anat Soc India. 2010;59:232-236.

19. Das AC, Saxena RC, Beg MAQ. Incidence of metopic suture in UP subjects. J Anat Soc India. 1973;22:140-143.
20. Bilodi AK, Agrawal BK, Mane S, Kumar A. A study of metopic sutures in human skulls. Kathmandu Univ Med J. 2003;2:96-99.

21. Nikolova S, Toneva D, Georgiev IA. Persistent metopic suture incidence and influence on the frontal sinus. Acta Morphol et Anthropol. 2016;23:1-8.

22. Göksal N. Füzyonunu tamamlamamış bir metopik sütür örneği. Hitit Üniv Sosyal Blm Ens Derg. 2018;11:2. 